\title{
Alert Generation and Cockpit Presentation for an Integrated Microburst Alerting System
}

\author{
Craig Wanke and R. John Hansman, Jr. ${ }^{* *}$ \\ Department of Aeronautics and Astronautics \\ Massachusetts Institute of Technology \\ Cambridge. Massachusetss USA
}

\begin{abstract}
Aler generation and cockpit presentation issues for low-level wind shear (microburst) alerts are investigated. Alert generation issues center on development of a hazard criterion which allows integration of both ground-based and airbome wind shear detection systems to form an accurate picture of the aviation hazard posed by a particular wind shear situation. A methodology for testing of hazard criteria through flight simulation has been developed. and has been used to examine the effectiveness and feasibility of several possible criteria. Also, an experiment to evaluate candidate graphical cockpit displays for microburst alerts using a piloted simulator has been designed.
\end{abstract}

\section{Nomenclature}

\begin{tabular}{|c|c|}
\hline$A D$ & approach degradation parameter (Eqn. 1) \\
\hline $\mathrm{C}_{\mathrm{L}}$ & aircraft lift coefficient \\
\hline$C_{D}$ & aircraft drag coefficient \\
\hline$d$ & glideslope indicator deviation \\
\hline D & aircraft drag \\
\hline F & F-factor (Eqn. 3) \\
\hline$\frac{g}{h}$ & $\begin{array}{l}\text { gravitational acceleration } \\
\text { altitude }\end{array}$ \\
\hline J & microburst impacl parameter (Eqn. 2) \\
\hline L & aircraft lift \\
\hline $\mathrm{m}$ & aircraft mass \\
\hline $\mathrm{T}$ & aircraft thust \\
\hline $\mathrm{V}$ & airspoed \\
\hline$W_{x}$ & horizontal wind velocity (tailwind positive) \\
\hline$W_{b}$ & vertical wind velocity (updraft posinive) \\
\hline $\mathrm{x}$ & groundirack distance \\
\hline$\alpha$ & angle of atrack \\
\hline$\gamma$ & wind-relative flight path angle \\
\hline$\rho$ & correlation coefficient \\
\hline
\end{tabular}

Research Assistant

Associate Professor, Associate Fellow AIAA

Copyright 1991 by M.I.T. Published by the American Institute of Aeronautics and Astronautics, Inc. with permission.

\section{Introduction}

Low altiude wind shear is the leading weatherrelated cause of fatal aviation accidents in the U.S. Since 1964, there have been 26 accidents artributed to windshear resulting in over 500 fatalities. 12 The localized intense downdrafis known as microbursts are the most dangerous form of wind shear, and pose a serious hazard to aircraft during takeoff or approach. For this reason, wind shear hazard deteccion and alering system development is a very active area of research (Fig. l). The variety of systems under development for wind shear detection and ground-to-air datalink. combined with the advent of electronic cockpit insurumentation. allow many options for implementation of an integrated wind shear waming system. The development of the optimal system configuration requires work in two major areas: (1) alen generation methodology and (2) information transfer and presentation to light crews.

\section{Background and Problem Definition}

\subsection{Alert Generation}

Several low-level wind shear detection systems, both ground-based and airbome, are currently operational or under development. The Teminal Doppler Weather Radar (TDWR) system is currenty under final stages of development and is scheduled for initial deployment in 1992. The Low Level Windshear

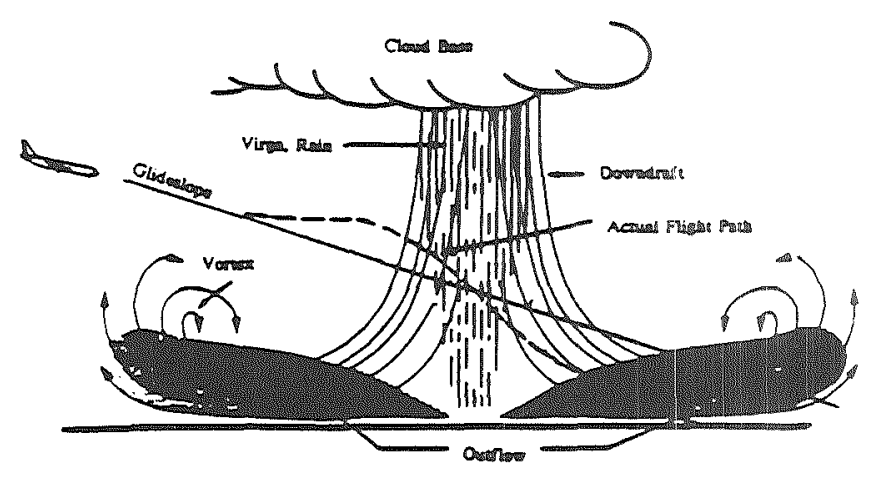

Figure 1. Aircrall emcounter with microburst on approsch 
Alert System (LLWAS), a system of on-airpont anemometers, is currently operational at many U.S. airports and is being expanded in some locations and integrated with TDWR in others. Also operational are airborne reactive systems, which provide wamings after a wind shear has been encountered. Several airborne look-ahead systems. including infrared, Doppler weather radar, and Doppler laser radar (lidar) systems are in the developmental stage. In the near future, almost any combination of the above systems may be available in a given siluation.

As a result. the first task for alert generation is to combine data from several systerns, which use different measurement techniques, into an estimate of the hazard posed by a particular wind shear event. If the detected hazard exceeds a pre-determined hazard threshold, an alert must be generated and disseminated to the affected aircraft. For safety reasons, the number of missed alerts must be minimized. For pilot confidence in the alerting system to remain high and for minimal disruption of airport operations, the alert should only occur in cases where the wind shear truly poses a threat. One essential element necessary to satisfy these requirements is accurate assessment of the wind shear hazard.

Accurate assessment of wind shear hazards, in turn, requires use of an effective "hazard criterion." The hazard criterion should be a quantity which can be directly measured or inferred from available measurements, and which accurately reflects the danger to aircraft posed by the low-level wind shear event being measured. An example of a microburst hazard criterion (currently used by the TDWR system) is "total divergence," which equals the maximum headwind change that could be experienced by an aircraft flying directly through the microburst. Due to the variety of different wind shear sensors available, accuracy is not the only requirement for good hazard criteria. To allow accurate combination ("fusion") of data from multiple sensors, a balance must be struck between 1) the most easily measured and accurate hazard criterion for each sensor used, and 2) use of the fewest different hazard criteria possible to make data fusion easier.

\subsection{Information Transfer and Presentation}

Once an alert has been generated, timely and effective presentation of the alert to the flight crew is required. A severe microburst event which occurred during the 1988 TDWR evaluation at Denver Stapelton airpor illustrates this point. ${ }^{3,4}$ On July 11, 1988 several microbursts of increasing intensity were detected by the TDWR system. Alerts were generated and disseminated via standard radio communications to five aircraft on approach. Only one of these aircraft aborted the approach prior to penetrating the area of microburst activity. The others, despite the alerts. did not recognize the threat until after penetration of the microbursts, resulting in one near accident and in all of the aircraft making missed approaches. Even though the alerts were accurate and produced well in advance of the approaches, verbal dissemination of the alerts proved ineffective and the advance warning was lost.

The message from this event is that alert dissemination and presentation needs to be carefully designed to allow effective alerting. Two new technologies will aid this process: 1) digital ground-toair datalinks such as the FAA's Mode-S system and 2) the electronic flight instrumentation systems (EFIS) in modern transport aircraft. Preliminary work has been done to compare the effectiveness of verbal, alphanumeric, and graphical modes of presenting uplinked wind shear alerts. Graphical alerts were found to result in improved decision-making, lower crew workload. and were preferred by flight crews. ${ }^{5.6}$

\subsection{Research Focus and Approach}

The work presented in this paper focusses on two of the major issues presented above: 1) wind shear hazard criteria, and 2) evaluation of prototypical graphical cockpit displays for integrated wind shear alerts. A methodology for testing of hazard criteria through flight simulation has been developed.

Preliminary runs have been performed for a set of possible hazard criteria, including that currently used by the TDWR system. The values of the possible hazard criteria for a set of modeled microburst windfields have been correlated with the flight path degradation experienced by a simulated aircraft flying through those windfields to obtain an estimate of usefulness.

The prototypical cockpit displays for wind shear alerts will be tested with a piloted flight simulation study. The experimental design has been completed, and active line pilots are being solicited as subjects.

\section{Evaluation of Microburst Hazard Criteria}

\subsection{Approach}

The danger to aircraft posed by a microburst is not a directly measureable quantity. A microburst "hazard criterion" is a directly measureable quantity which provides an indication of the aviation hazard. Therefore. the assumption made for this experiment was that a good hazard criterion should correlate well with the impact of a microburst on an aircraft trajectory.

In order to evaluate hazard criteria based on this assumption, 1) a nominal microburst encounter situation, and 2) a quantitative measure of the effect of 
a microburst on an aircraft trajectory were defined. The nominal condition was chosen to be a microburst encounter on final approach. In addition, it was assumed that the pilot or autopilot was unaware of the presence of the microburst, and hence attempted only to maintain the glidepath with a "normal" control strategy. This nominal case is used only to allow the comparison of hazard criteria under a consistent situation; it is intended that the results will be extended to include other situations such as takeoffs.

For the nominal case (approach), either dropping below the glideslope or loss of airspeed must be considered hazardous conditions. To quantify this, an "Approach Degradation" (AD) parameter (similar in concept to those used in References 7 and 8) was defined which combines both glideslope deviation and airspeed loss:

$$
A D \equiv \sqrt{\left(\frac{d_{\text {bow }}}{d_{\text {full scale }}}\right)^{2}-\left(\frac{V_{\text {ref }}-V}{V_{\text {ref }}-V_{\text {stall }}}\right)^{2}}
$$

$$
\text { where } \mathrm{d}_{\mathrm{low}}=\text { "dots" below glideslope }
$$

In developing this measure, it was assumed that a critical situation develops if either (1) the aircraft drops two "dots" $\left(0.7^{\circ}\right)$ below the glideslope", or (2) the aircraft's airspeed drops to the stall airspeed. Thus, either of these situations was defined as a "unit hazard." The root-mean-square of the fractional hazards due to falling below the glideslope or losing airspeed is therefore a point measurement of the approach degradation.

The angular error vs. glideslope measurement was chosen rather than altitude error to emphasize the greater danger due to being below glideslope at lower altitudes. Also, deviations above glideslope or velocity changes above trim are not included in the computation of $\mathrm{AD}$; the terms inside the parentheses in the above equation can only take positive values.

To evaluate the impact of the overall windfield on the approach, this parameter is integrated over the entire approach to produce the overall "microburst impact" parameter J.

$$
J \equiv \int[A D] d t \quad \text { over entire approach }
$$

\footnotetext{
"Two "dots" of glideslope deviation means that the pilot's glideslope deviation indicator has reached full scale in the low direction, which is the equivalent of falling $0.7^{\circ}$ below the $3^{\circ}$ glideslope as measured from the runway thrèshold.
}

A series of aircraft simulation runs were performed. using this nominal condition and a series of highresolution modeled microburst windfields. The value of the microburst impact parameter was computed for each run. A set of possible microburst hazard criteria were then computed for each of the modeled windfields. The hazard criteria were then evaluated by calculating the linear correlation coefficient between each of the hazard criteria and the microburst impact parameter for the complete set of simulation runs. Note that "correlate well" as used to define a good hazard criterion has been specialized to mean good linear correlation for the purposes of this analysis. Linear correlation is used because it is 1 ) desirable for simplicity in applying the hazard criterion and 2) easily evaluated by computing the correlation coefficient. Two complete sets of runs were performed, using the same windfields but different autopilot models, in order to show the insensitivity of this analysis to the control strategy employed.

\subsection{Candidate Hazard Criteria}

The following set of hazard criteria was chosen for examination in the simulation runs.

1) Total divergence, $\Delta U$ (headwind-to-tail wind shear across the event)

2) Mean shear, $\Delta U / \Delta R$, defined as total divergence divided by the shear distance (the distance between the headwind and tailwind peaks)

3) Peak F-factor (defined below)

4) Largest F-factor exceeded for a given distance $(1500,300,450,6000$ foot lengths were tested)

5) Largest mean F-factor over a given distance $(1500,3000,4500,6000$ foot lengths were tested)

The total divergence, as mentioned above, is the criterion currently used in TDWR operational evaluations for both alert thresholds and intensity reporting. A measurement of greater than 30 knots divergence by the radar triggers a microburst alert (with the divergence reported as an " $X$ knot loss") and a measurement of greater than 20 but less than 30 knots is given as "wind shear with loss." Mean shear is an alternative criterion, which could be easily computed from TDWR measurements; it is obtained by dividing the divergence value by the radial distance across which it is measured.

The "F-factor" hazard criterion, proposed by researchers at NASA Langley Research Center ${ }^{10}$, is based on the impact of a microburst windfield on the total energy (kinetic plus potential) of the aircraft. It is a direct measure of the loss of potential rate-of-climb (or loss of effective thrust-to-weight ratio) due to the 
immediate windfield. It is dependent on the time rate of change in the aircraft frame of the tailwind velocity, the vertical wind velocity, and the aircraft airspeed. A derivation of $F$ based on longitudinal aircraft equations of motion is available in References 10 and 11 .

$$
F \equiv \frac{W_{x}}{g} \cdot \frac{W_{h}}{V}
$$

$F$-factor is a nanural measurement for reactive sensors based on inertial instruments, since all of the parameters can be directly measured. Forward-looking infrared systems under development also derive $F$. computing it from the temperature gradient sensed along the aircraft flight path. ${ }^{10}$ TDWR, however, must infer $F$ since the vertical winds cannot be directly neasured

Hazard criterion 4 is computed by taking the largest $F$-factor value which is exceeded for a minimum of the specified distance along the flight path. This is analogous to having an airborne sensor system, focussed ahead of the aircraft, which generates an alert if the measured $F$ exceeds a given threshold value for the specified distance. Since $F$ is an instantaneous measurement. taking the maximum $F$ over a distance is similar to an integration and indicates the magnitude of total performance loss over that distance. Similarly, hazard criterion 5 takes the largest $F$-factor computed from a running average over the specified distance ahead of the aircraft.

\subsection{Aircraft/Microburst Interaction Simulation}

The aircraft/microburst interaction simulation (Figure 2) was based on longitudinal point-mass equations of motion in wind axes, which allows flight in a vertical plane only with no short-period pitching dynamics. The aircraft data used (provided by NASA Langley Research Center, and used in Reference 11) was for a Boeing 737-100 aircraft, and included nonlinear curve fits for $C L$ and $C D$ as functions of angleof-attack, flap position, and gear position.

$\dot{V}=\frac{I_{m}}{m} \cos \alpha-\frac{D}{m} \cdot g \sin \gamma \cdot \dot{W}_{x} \cos \gamma-\dot{W}_{h} \sin \gamma$

$\dot{\gamma}=\frac{1}{V}\left[\frac{I}{m} \sin \alpha+\frac{L}{m}-g \cos \gamma+\dot{W}_{\mathrm{z}} \sin \gamma-\dot{W}_{h} \cos \gamma\right]$

$\dot{x}=V \cos \gamma+W_{x}$

$\dot{h}=V \sin \gamma+W_{h}$

$\alpha=\theta-\gamma$

$C_{L}=f(\alpha$, flaps, gear position $)$

$C_{D}=f(\alpha$, flaps, gear position $)$

A multivariable controller for airspeed and flight path angle was then designed for this model. This inner-loop controller took the form of a fully coupled proportional-plus-integral cascade compensator. In addition, an outer loop was closed around flight path angle to track the glideslope. Two versions of the outer loop (glideslope tracking) compensator were used. The baseline compensator was a simple gain, and produced a fairly slow response. The second version was a dynamic compensator which produced a faster response, and tended to weight glideslope deviations more heavily than airspeed deviations. The "slow" controller had a natural frequency of $0.1 \mathrm{rad} / \mathrm{sec}$, while the "fast" controller had a naurral frequency of 0.4 $\mathrm{rad} / \mathrm{sec}$.

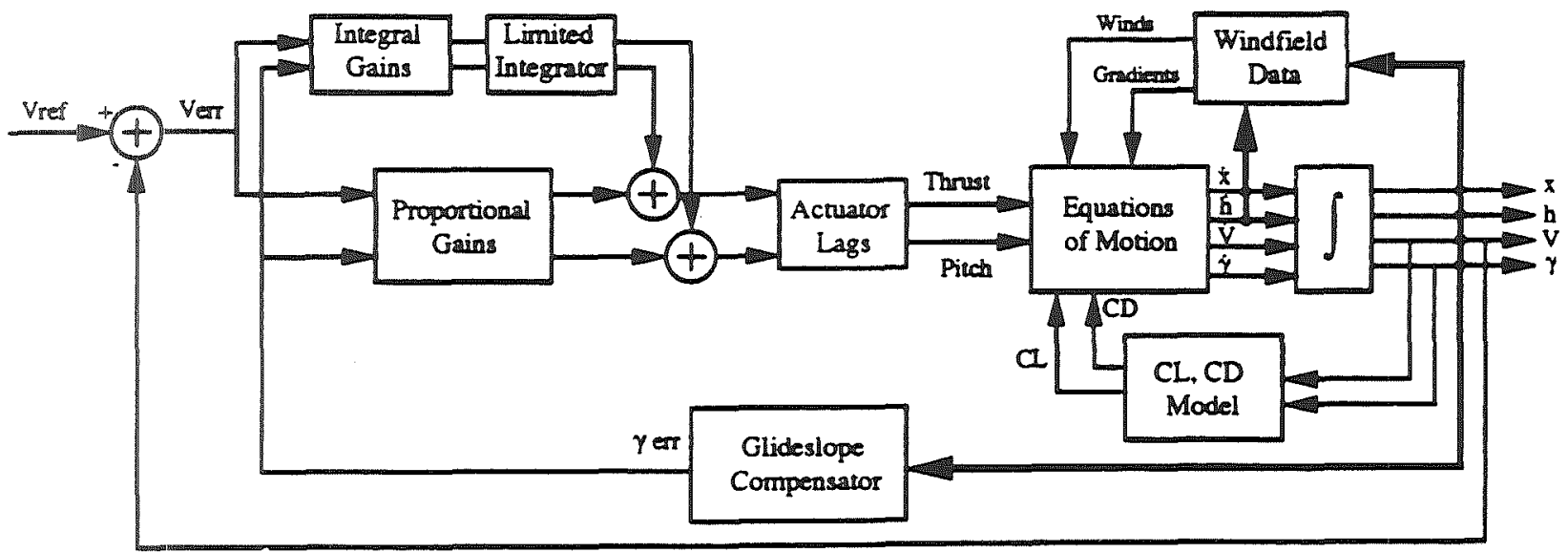

Figure 2. Simulation Block Diagram 
The windfield data used was generatred by the Terminal Area Simulation System (TASS) ${ }^{12}$, and is a simulation of a complex multiple microburst event which occurred at Denver-Stapelton airport on July 11 , 1988. This event caused one near accident and a total of five aircraft to make missed approaches. and has been extensively documented in Reference 3. Data from five times during this event was available, and 12 paths through various parts of the windfield at various times were selected for analysis. These paths all penetrate the approximate center of at least one microburst, and vary in total divergence (at $300 \mathrm{ft} \mathrm{AGL}$ ) from 42 to $70 \mathrm{knots}$. Shear distances (measured from peak headwind location to peak tailwind location) vary from 6592 feet up to 20000 feet. Figure 3 illustrates one of the horizontal velocity fields from the TASS model. and some of the paths used for the approaches.

A typical microburst windfield (as encountered in one of the simulation runs) is shown in Figure 4. The aircraft first encounters a performance-increasing headwind. This is followed by a downdraft and a rapid transition from headwind to tailwind, both of which tend to drive the aircraft below glideslope and reduce airspeed. These effects are aggravated if the pilot or autopilot is unaware of the microburst. and reduces thrust during the headwind portion of the event to maintain glideslope tracking.

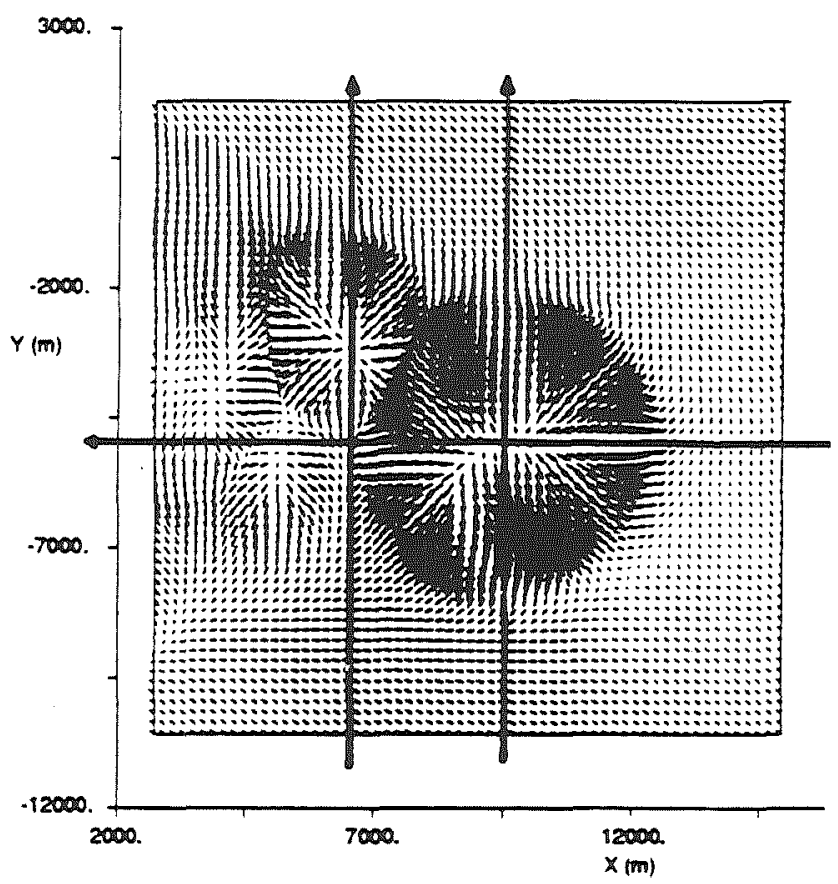

Figure 3. TASS windfield for $7 / 11 / 88$ at 2212.75 UTC. This is a vector plot of the horizontal plane sinds at 271 feet AGL. The lines indicate some of the paths used in the simulation runs (windfields 2,3 , and 5).
For each windfield, an approach was made such that the aircraft penetrated the core of the microburst at approximately $1.5 \mathrm{~nm}$ (at an altitude of 400 to 500 feet) from the desired touchdown point. The aircraft was trimmed for approach at 140 knots with landing gear extended and flaps set at $25^{\circ}$. The available thrust was limited to approach maximum, which results in a maximum thrust-to-weight ratio of approximately 0.17 . As stated above, it is important to note that the assumption was made that the pilot or autopilot was unaware of the presence of the microburst. and hence attempted only to maintain the glidepath with a "normal" control strategy.

The actual simulation was run on a Sun $3 / 80$ workstation using MATRDX $x$ SYSTEM_BUILD software by Integrated Systems. Inc. The altitude and airspeed histories for a sample run are presented in Figure 5.
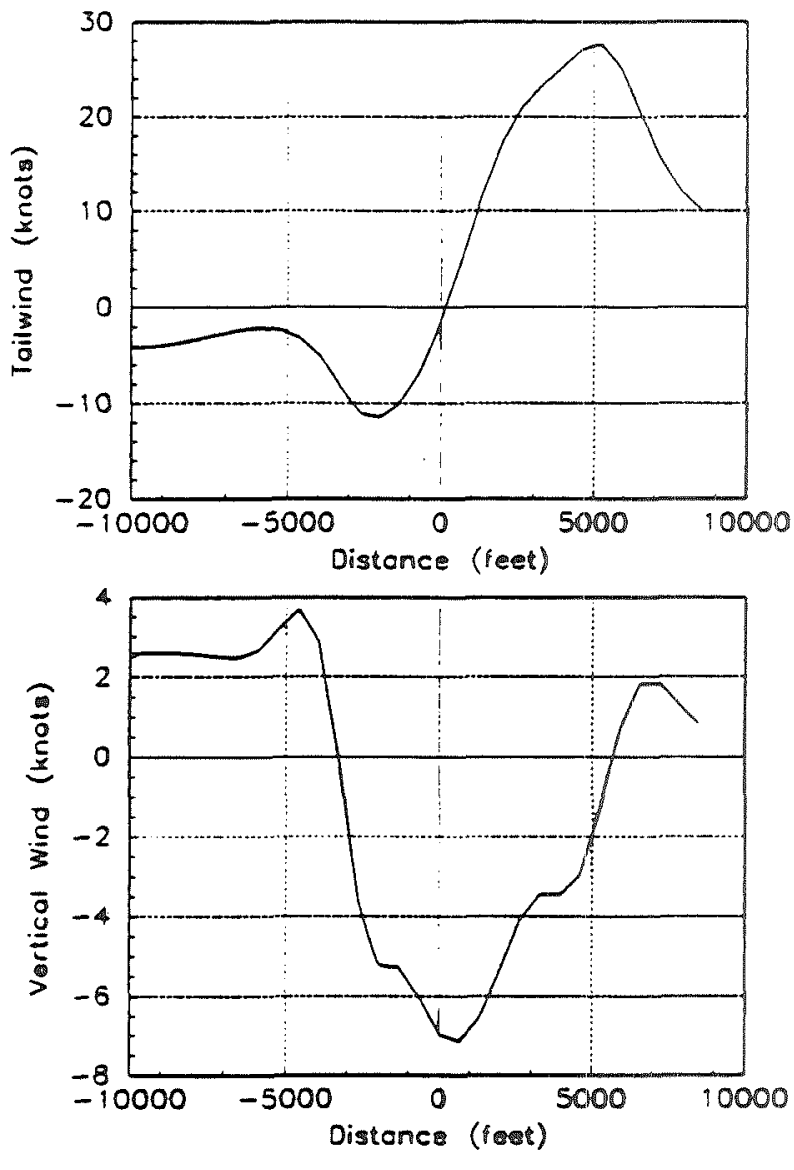

Figure 4. A typical microburst wind profle. These winds were encountered by the aircraft during one of the simulated approaches. 

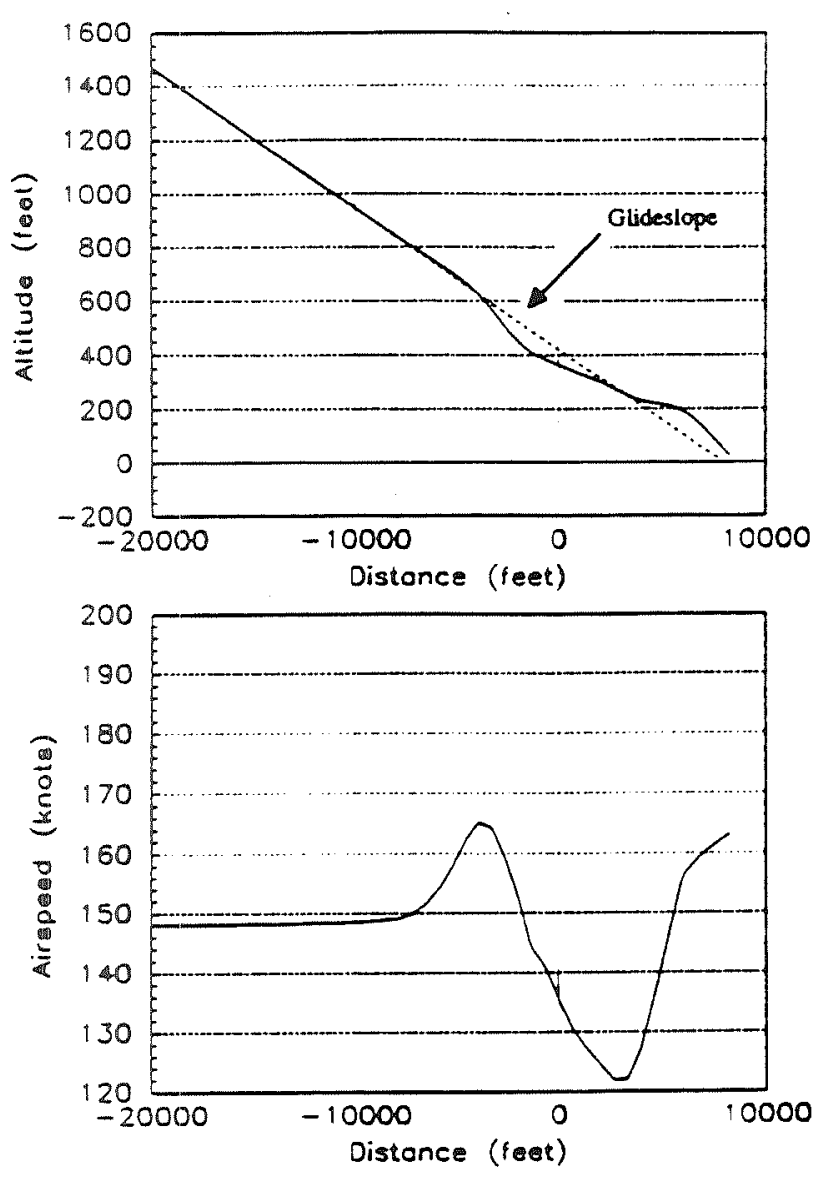

Figure 5. Sample altitude and airspeed histories for a simulation run

\section{Results and Discussion}

The primary result of each simulation run was the final value of J, the microburst impact parameter. The hazard criteria were then applied for each windfield. Divergence and mean shear were computed from a 300 foot AGL path through the windfield along the approach path to simulate a TDWR-like measurement. F-factor parameters were computed from the actual Ffactor history experienced by the aircraft in the simulation. A linear correlation analysis was then performed for each of the hazard criteria vs. J Table 1 presents the results for the set of 12 runs using the baseline "slow" glideslope control strategy.

The criteria which showed the best correlation ( $\rho>0.81$ ) for this set of runs were mean shear, largest $F$ exceeded over 1500 or 3000 feet, and largest mean $F$ over 3000 to 6000 feet. The peak F-factor along the flight path does not correlate as well. Measuring the largest F over 6000 feet correlates very poorly. This is
Table 1. Correlation coefficients between bazard criteria and microburst hazard parameter

\begin{tabular}{|l|c|}
\hline \multicolumn{1}{|c|}{ Hazard Criterion } & Correlation coefficient. \\
\hline \hline Divergence & 0.486 \\
Mean shear & 0.875 \\
Peak F & 0.711 \\
Largest F exceeded over: & \\
1500 feet & 0.811 \\
3000 feet & 0.858 \\
4500 feet & 0.779 \\
6000 feet & 0.445 \\
Largest mean F over: & \\
1500 feet & 0.743 \\
3000 feet & 0.791 \\
4500 feet & 0.801 \\
6000 feet & 0.790 \\
\hline
\end{tabular}

logical, since the distance over which critical values of shear and downdraft were experienced was generally less than 6000 feet. Total divergence, the criterion currently used by TDWR, did not correlate very well $(p=0.486)$. A comparison of the divergence and mean shear results is shown in Figure 6.

The greater effectiveness of mean shear (over divergence) is not surprising, since the wind shear threat is due to loss of energy from both rapid change in horizontal wind velocity and from vertical wind velocity (downdraft). The mean shear criterion is an improvement over divergence in two ways: 1) it provides a better measure of the effect of changing horizontal winds, since due to the dynamics of the aircraft. the rate of headwind change is as critical as the amount of headwind change, and 2) due to mass continuity, the magnitude of the downdraft is related to the rate of headwind change, and therefore the mean shear value also accounts in some fashion for the downdraft component.

The varying results for the criteria based on $F$ demonstrate a problem with using a point measurement to predict hazard. Clearly, $F$ must be significant over some distance/time to be truly hazardous. Microbursts, however, have some wind profile shape similarity. If all microburst windfields were geometrically similar, the peak $F$ would basically define the hazard posed by a given microburst. Since this is not the case. measuring/averaging $F$ over a distance seems to be an effective strategy, yielding some information about integrated energy loss as well as point hazard. The problem lies in selection of the appropriate threshold length (for criterion 4) or averaging window length (for criterion 5). Results for several of the F-based criteria are shown in Figure 7. 

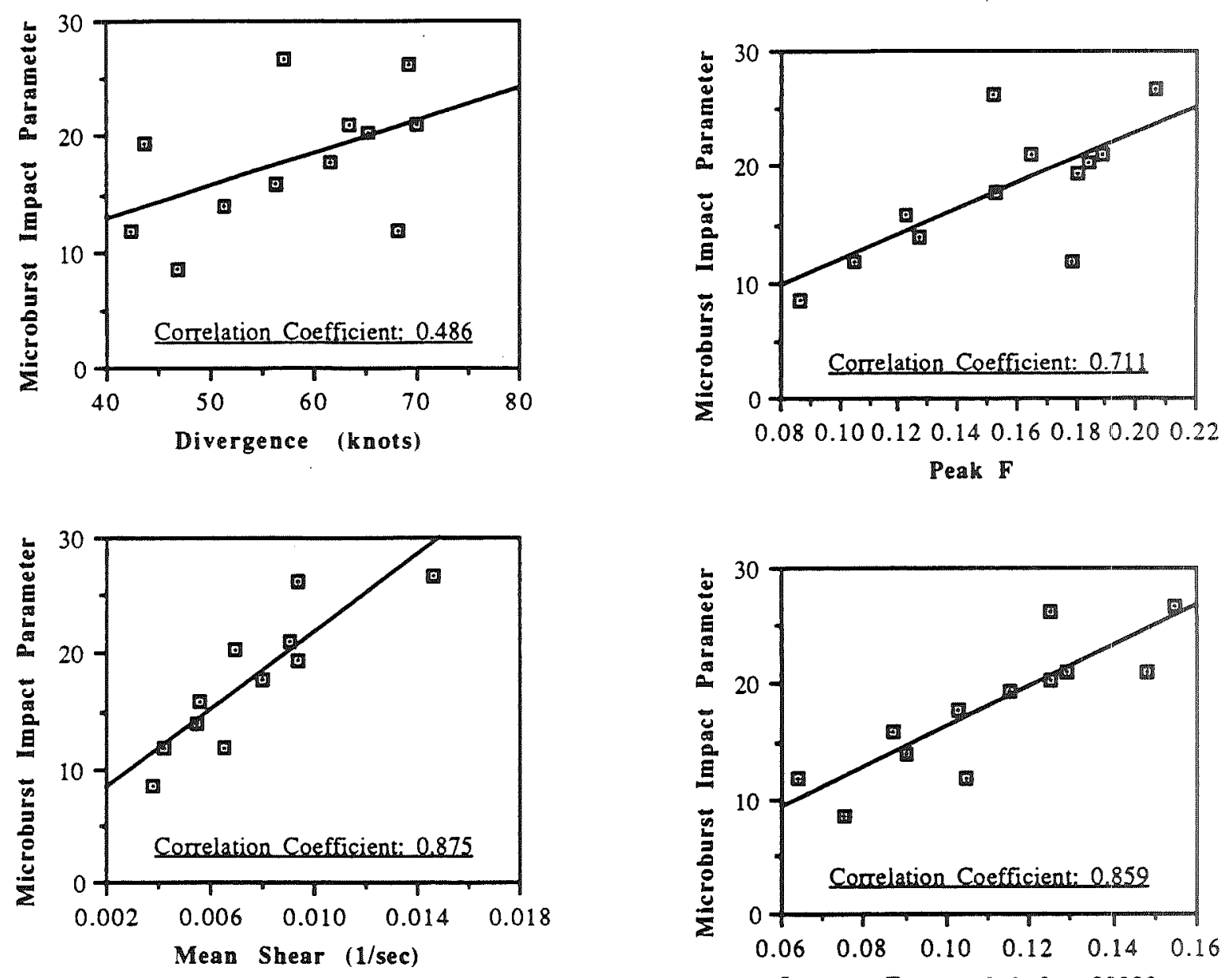

Figure 6. Microburst impact parameter vs divergence and mean shear hazard criteria

For the "largest $F$ exceeded" criterion, 3000 feet proved to be the best distance, although 1500 and 4500 foot distances also gave good correlation. Using the averaging technique, it was found that all the distances tested worked fairly well, with the best results for 4500 feet. Neither of these criteria were very sensitive to the distance chosen. The "largest F exceeded" criterion produced better results for the shorter distances, and is simpler to evaluate, which indicates that it may provide a better, earlier warning when used with an airbome look-ahead sensor. It is important to note, however, that the results for the different distances are most likely somewhat dependent on the model windfield used. Also, the advantage of criterion 4 over criterion 5 is not very significant in view of the limited number of runs performed.
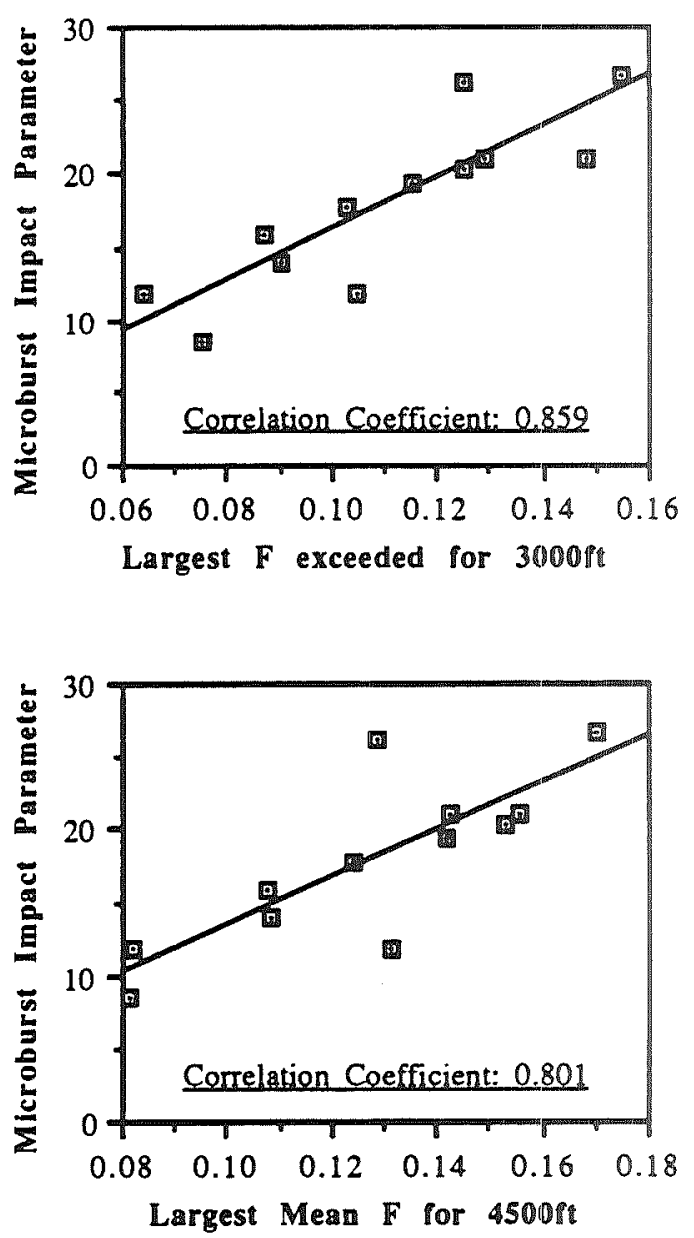

Figure 7. Microburst impact parameter vs. several F-based hazard criteria 


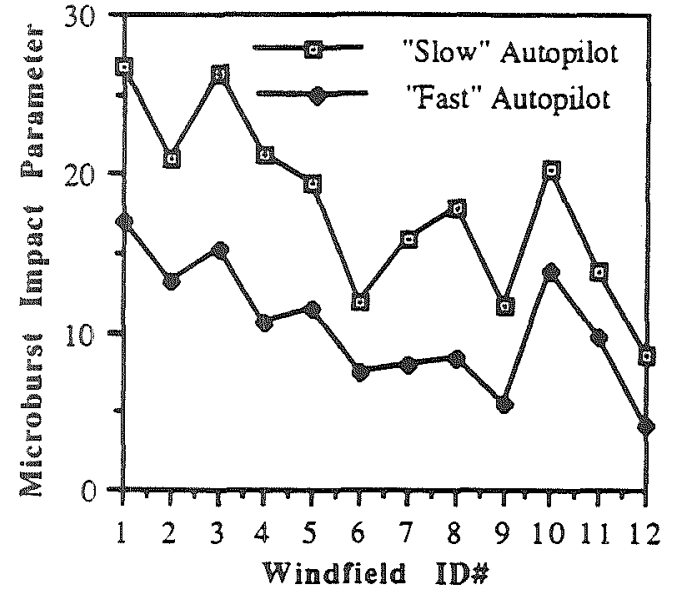

Figure 8. Microburst impact parameter for each windfield, for two different glideslope controllers

In order to examine the effects of control strategy on the above results, an additional set of runs was performed, using the "fast" glideslope controller with the same windfields. This faster controller resulted in lower values of $J$ for all of the approaches (Figure 8). However, the correlation coefficients for the hazard criteria were not significantly different than those from the first set of runs (Table 2). This indicates that, although the final magnitude of $J$ (and hence the hazard) depends on the control strategy employed, hazard criteria which correlate well with the microburst impact parameter for one control strategy will still correlate well for another strategy. A similar effect would be seen when comparing results for aircraft with differing performance capabilities.

Table 2. Correlation coefficients for runs with "Iast" glideslope controller

\begin{tabular}{|l|c|}
\hline Hazard Criterion & Correlation coefficient. $P$ \\
\hline Divergence & 0.491 \\
Mean shear & 0.845 \\
Peak F & 0.814 \\
Largest Mean F (4500ft) & 0.888 \\
\hline
\end{tabular}

\subsection{Analysis Limitations}

Before drawing conclusions from the above analysis, some limitations should be discussed. The most important is that all the microburst windfields analyzed came from a single day (in fact, all within 10 minutes) due to the limited amount of high-resolution windfield model data available. Although a fairly well distributed set of microburst intensities and sizes were available in this data set, the results may be biased by some feature of the TASS model or by characteristics particular to the meteorological conditions on the day simulated. This analysis will be extended to include additional data sets as they become available.

A further limitation is the use of a single aircraft model of a fairly small transport aircraft. Use of a different transport aircraft model or a different pilot or autopilot model would clearly result in different values of $J$. The higher-bandwidth control strategy, for example, lowered the final $\mathrm{J}$ value for all runs. This did not, however, significantly alter the correlation results, since the difference in approach tracking due to the different control strategy was roughly the same for all microburst encounters. Using a different transport aircraft model would have a similar effect. It is also interesting to note that the only control tradeoff available from an energy standpoint is whether airspeed control or altitude control is weighted more heavily. The microburst impact parameter includes both of these deviations. The extension of this analysis to include general aviation aircraft is also under consideration; GA aircraft have much slower approach speeds and considerably different dynamic characteristics. Also, as discussed previously, these results are specific to the nominal case chosen (approach), and need to be extended to cover takeoff situations as well.

In addition, the evaluation of the hazard criteria did not include measurement limitations. For example, the measurement of divergence and mean shear at 300 feet AGL was done to "simulate" a ground-based radar like TDWR, but does not account for measurement details such as averaging across the radar beamwidth, for example. Similarly, $F$ was taken from the aircraft history after the simulation run, and not from a simulation of a forward-looking infrared or other airborne sensing system.

Finally, it should be noted that in some past wind shear related accidents (the crash of Delta 191 at DFW in 1985, for example) there were short-scale pitching and rolling motions of large enough amplitudes to considerably affect the controllability and performance of the aircraft. The disturbances which caused these oscillations are not generally included in windshear models (due to their small length scales) and are not visible in dual or triple doppler radar wind measurements (due to finite resolution). These disturbances are also not included in $J$ or in any of the hazard criteria.

\subsection{Implementation Issues}

The second requirement for a good hazard criterion, as stated in Sectoon 2.1, is that it must be measureable by the available wind shear sensors. Based on the 
correlation coefficients, mean shear and largest F-factor exceeded over 3000 feet were the best criteria. For a ground-based radar like TDWR, which cannot directly measure vertical velocity and hence cannot directly measure $F$, mean shear is a natural measurement. The TDWR system currently generates accurate values of both divergence and shear distance. Airbome infrared systems now under development measure a temperature gradient at some point ahead of the aircraft, which is converted to a point measurement of $F$. Using the Fbased criterion would be natural in this case. since the F-over-a-distance alert criterion reduces to the $\mathbb{R}$ system sensing an $\mathrm{F}$ above a designated threshold for a designated period of time. Current airborne reactive sensors measure $F$ through a low-pass filter, which is similar to averaging $F$ over a distance. Clearly the measurement technique used has a strong bearing on which hazard criterion is appropriate.

Once the criterion has been established, the question that remains to be answered is: what value of the hazard criterion should trigger an alert? This question is difficult, since it requires evaluation of how much wind shear hazard is "acceptable" and how much is a threat. The analysis technique used above cannot answer this question. The hazard criteria evaluated above will most likely correlate similarly with the microburst impact parameter if other aircraft configurations, types, or autopilots (such as in Figure 8) are used, but there will be a scaling difference. In other words, applying a good hazard criterion to two different microbursts will indicate which one is a greater threat, but will not indicate that both might be hazardous to a heavily loaded aircraft with a low excess thrust-to-weight ratio, while neither may be hazardous to a nearly empty aircraft. Altematively, two aircraft with different autopilots (or with two pilots of differing skill) might exhibit a similar difference in hazard threshold. A margin of safety must be included in definition of the alerting threshold, and all classes of aircraft to which the alert will be issued need to be considered.

\section{Planned Piloted Simulator Study}

\subsection{Goals}

The goal of this study is to evaluate candidate graphical cockpit displays for wind shear (microburst) alerts on aircraft equipped with an Electronic Flight Instrumentation System (EFIS). For this evaluation, graphical microburst alerts will be displayed on the Electronic Horizontal Situation Indicator (EHSI), a moving-map type navigational display.

The experiment is designed to evaluate the following:
1) General pilot reactions to the use of the EHSI for microburst alert presentation and to some baseline graphical display formats

2) The effect of displaying either only "threatening" microbursts or both threatening and less intense microbursts on pilot decision making and missed approach planning

3) The effect of reflectivity on pilot decisionmaking (i.e. will the subjects react differently to "dry" microburst events than to "wet" events)

4) Pilot reaction to presenting "fused" alerts (where the sensors used are not evident) vs. presenting discrete alerts (where a different representation is used for airborne sensors than for ground-based sensors)

5) The proximity to a hazard at which the subjects feel a missed approach must be initiated.

The results of this evaluation will be used to determine critical design items for implementation of integrated graphical wind shear alerts.

\subsection{Experimental Methodology}

The experiment will be performed with the MIT Advanced Cockpit Simulator. a part-task simulation of an advanced transport aircraft equipped with both an EFIS and a Flight Management Computer (FMC). The simulator, an upgraded version of that used in the modes of presentation comparison discussed in Section 2.2 , includes all primary electronic flight displays, display controls, autoflight systems, and a partial simulation of the FMC.

A sample candidate EHSI display format for microburst alerts is shown in Figure 9. Remotely detected microbursts are presented as solid red circles or "bandaid" shapes in the appropriate location on the map display. The method by which the microbursts are being detected is transparent to the pilot on this display; an altemative display in which airbome remote sensor information is distinguished from ground-based information will also be tested. Reactive alerts, triggered by penetration of a microburst event, will be displayed as a flashing red circle directly around the "ownship" symbol. In one methodology, only microbursts which have been judged "threatening" are displayed. Another display option is to also show "secondary" events, which are measured areas of wind shear (weak microbursts) which do not excesd the hazard threshold. These could be displayed as open red circles or bandaid shapes to distinguish them from hazardous microbursts. 
The evaluation will be performed in two different settings: 1) static display presentation, and 2) real-time simulated approaches. The static display presentation will be used to obtain pilot input on the general display format and display options in a non-flying situation. The simulated approaches will test the display in flight situations. A set of scenarios have been designed to obtain both quantitative data and pilot opinions on each of the items on the above list. For example, the same threatening microburst situation will be flown using several different display options. and differences in the pilots' handling of the situation will be observed.

Active line pilots who are currently flying EFIS/FMC equipped transport aircraft will be recruited for this experiment. The flying portion of the experiment will be performed in conjunction with an electronic approach plate experiment. which will attenuate the anticipation caused by repeated microburst alerts. Scenarios with non-threatening microbursts present and with no microbursts present will also be includech, to prevent the subjects from developing a systernatic way of handling microburst threats.

\section{Conclusions}

Issues related to the development of an alerting system for microbursts in the terminal area have been studied. Two specific issues have been addressed: 1) identification of a good criterion for microburst hazard assessment. and 2) evaluation of graphical cockpit displays for presentation of microburst alerts.

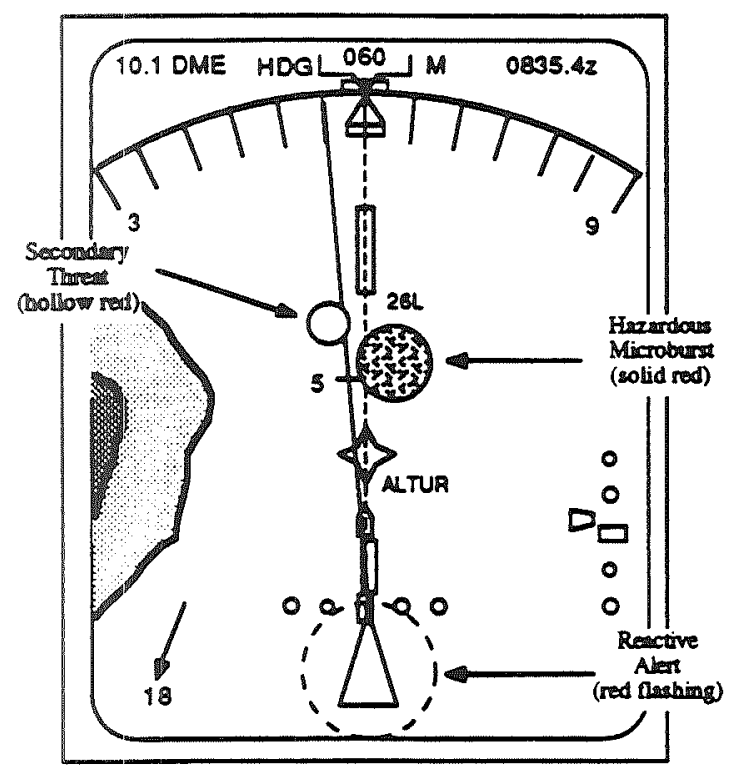

Figure 9. Candidate EHSI display format
A methodology for evaluating microburst hazard criteria has been developed. based on batch flight simulations of aircraft on approach through microburst windfields. A measure of the impact of a microburst on an aircraft's approach trajectory has been defined. which includes both airspeed losses and glideslope deviations. Hazard criteria are evaluated by calcularing the linear correlation coefficient between values of the hazard criteria and the values of the microburst impact parameter for several approaches through different microburst windfields. A preliminary evaluation of a selected set of hazard criteria has been performed. The results indicate that the total headwind change along the aircraft flight path (referred to as "total divergence") does not correlate well with the approach degradation caused by microbursts. However, the "mean shear," computed by dividing the total divergence by the distance over which it occurs, correlates very well with approach degradation. Also, application of the " $F$ factor" hazard criterion (a measure of the aircraft energy loss caused by the windfield) over certain distances proved to be an effective predictor of approach degradation. Finally, it was found that the correlation results obtained from runs using two different autopilot models were not significantly different.

An experiment has been designed to evaluate options for graphical cockpit display of microburst alerts. The experiment, to be performed on a part-task simulator with electronic flight instrumentation, will obtain pilot feedback and performance data on candidate graphical display options.

\section{Acknowledgements}

This work was supported by the MIT Lincoln Laboratory and the National Aeronautics and Space Administration (NASA) under contract BARR-10-119, and the Federal Aviation Administration and NASA under grant NGL-22-009-640. The authors would like to thank Steve Campbell at MIT Lincoln Laboratory for information on the TDWR system and general advice and support, David Hinton at NASA Langley Research Center for the aircraft simulation model data, input on the use of F-factor, and suggestions for design of the candidate graphical display format, and Fred Proctor of MESO. Inc. for the data from the TASS model.

\section{References}

1. National Research Council, Low Altitude Wind Shear and Its Hazard to Aviation, National Academy Press, 1983. 
2. Wolfson, M.M., "Characteristics of Microbursts in the Continental United States," The Lincoln Laboratory Journal, Vol. 1, No. 1, Spring 1988.

3. Schlickenmaier, Herbert W., "Windshear Case Study: Denver, Colorado, July 11, 1988." Federal Aviation Administration, DOT/FAA/DS-89/19, 1989.

4. Hansman, R. J.. and Wanke, C., "Cockpit Display of Hazardous Windshear Information," AIAA Paper 89-0808, January 1989.

5. Wanke, C.. Chandra, D., Hansman, R. J., and Bussolari, S. R.. "A Comparison of Voice and Datalink for ATC Amendments and Hazardous Wind Shear Alerts," 4th International Symposium on Aviation and Space Safety, Toulouse, France. 20-22 November 1990.

6. Wanke, C., and Hansman, R. J., "Hazard Evaluation and Operational Cockpit Display of Hazardous Windshear Information," AIAA Paper 90-0566, January 1990.

7. McCarthy, J., Blick, E. F., and Bensch, R. R., Jet Transport Performance in Thunderstorm Wind Shear Conditions, NASA CR-3207, 1979.

8. Turkel, B. S., Kessel, P. A., and Frost, W., Feasibility Study of a Procedure to Detect and Warn of Low-Level Wind Shear, NASA CR-3480, 1981.

9. Merritt, M. W., Klingle-Wilson, D., and Campbell, S. D., "Wind Shear Detection with Pencil-Beam Radars," The Lincoln Laboratory Journal, Vol. 2, No. 3, 1989.

10. Bowles, R. L., "Reducing Windshear Risk Through Airborne Systems Technology," 17th Congress of the International Council of the Aeronautical Sciences, Stockholm, Sweden, September 9-14, 1990.

11. Hinton, David A., Relative Merits of Reactive and Forward-Look Detection for Wind-Shear Encounters During Landing Approach for Various Microburst Escape Strategies. NASA TM-4158, DOT/FAA/DS-89/35, February, 1990.

12. Proctor, F. H., The Terminal Area Simulation System-Volume I: Thearetical Formulation; Volume II: Verification Cases, NASA CR -4046 and CR-4047, DOT/FAA/PM-86/50, 1987. 